\title{
Pengaruh Pemberian Pijat Bayi Terhadap Kenaikan Berat Badan Bayi Umur 0-6 Bulan Di BPS Bunda Bukittinggi
}

\author{
Baby Massage Giving Effect To The Weight Gain In Infants 0-6 Months At BPS Bunda \\ Bukittinggi
}

\author{
Mariza Elvira', Siti Azizah ${ }^{2}$ \\ ${ }^{1,2}$ Akper Nabila Padang Panjang Jl. Dr. H. Kamarullah No.1 Bukit Surungan Padang Panjang \\ Email : mariza_elvira@yahoo.com
}

Naskah masuk: 12-05-2017

Naskah diperbaiki: 29-05-2017

Naskah disetujui:19-06- 2017

\begin{abstract}
The massage is not only done when the baby is healthy, but also on sick or fussy babies and infants has become routine care after birth. The purpose of this study was to determine the effect of infant massage on weight gain in infants aged 0-6 months. This type of research is Experimental with Quasy Experiment. The population in this study was 0-6 month-old baby. The sample amounted to 24 people consisting of 12 people who were given infant massage and 12 people were not given infant massage with technique sampling nonprobability. Data was collected using a computerized questionnaire then processed in the univariate and bivariate analyzes. The results obtained infant weight gain on average increased weight infants fed infant massage is 800 gram/month and on average increased weight infants who were not given the baby massage is $233.33 \mathrm{gram} / \mathrm{month}$. Results of statistical test $p$ value $=0.000$ visible means no significant difference on average between giving a massage in infants with weight gain in infants aged 06 months. The conclusion can be drawn that the baby is gaining weight rapidly increases with doing baby massage, and also advice it to parents to always perform routine infant massage on baby.
\end{abstract}

Keywords $\quad$ : Massage baby, Improved Weight Infants

\begin{abstract}
ABSTRAK
Pijat bayi di Indonesia pelaksanaan di masyarakat desa masih dipegang oleh dukun bayi. Selama ini pemijatan tidak hanya dilakukan bila bayi sehat, tetapi juga pada bayi sakit atau rewel dan sudah menjadi rutinitas perawatan bayi setelah lahir. Tujuan penelitian ini adalah mengetahui pengaruh pemberian pijat bayi terhadap kenaikan berat badan bayi umur 0-6 bulan di BPS Bunda. Jenis penelitian yang digunakan bersifat Experimental Desaign dengan Quasy Experiment. Populasi dalam penelitian ini adalah bayi berumur 0-6 bulan. Sampel dalam penelitian ini berjumlah 24 orang yang terdiri dari 12 orang yang diberikan pijat bayi dan 12 orang yang tidak diberikan pijat bayi dengan tekhnik pengambilan sampel Nonprobability Sampling. Data dikumpulkan dengan menggunakan kuesioner kemudian diolah dengan komputerisasi di analisis dengan univariat dan bivariat. Hasil penelitian univariat didapatkan hasil tentang pelaksanaan pijat bayi sebanyak 12 orang (100\%) dan yang tidak melakukan pijat bayi sebanyak 12 orang $(100 \%)$. Hasil kenaikan berat badan bayi didapatkan rerata kenaikan berat badan bayi yang diberikan pijat bayi adalah 800 gram/bulan dan rerata kenaikan berat badan bayi yang tidak diberikan pijat bayi adalah 233.33 gram/bulan. Hasil uji statistik didapatkan nilai $\mathrm{p}=0,000$ berarti terlihat ada perbedaan yang signifikan antara rerata kenaikan berat badan bayi yang diberikan pijat bayi dan yang tidak di berikan pijat umur 0-6 bulan di BPS Bunda. Kesimpulan yang dapat diambil bahwa kenaikan berat badan bayi lebih cepat meningkat dengan dilakukannya pijat bayi, Di sarankan kepada ibu agar selalu rutin melakukan pijatan bayinya.
\end{abstract}

Kata Kunci $\quad$ : Pijat Bayi, Peningkatan Berat Badan Bayi

\section{PENDAHULUAN}

Masa bayi merupakan tahapan dimana pertumbuhan dan perkembangan yang sangat cepat dimulai dari bayi itu lahir hingga nanti berusia 1 tahun. Usia perkembangan bayi terbagi menjadi 2 
yaitu neonatus dari lahir hingga berusia 28 hari dan bayi dari 29 hari hingga 12 bulan (WHO, 2013). Sedangkan menurut Roesli (2013) yang dikatakan bayi adalah anak dengan usia 0 sampai 12 bulan.

Pada proses pertumbuhan dan perkembangan anak, orang tua dan keluarga memiliki peran yang sangat penting bukan hanya untuk memenuhi nutrisi yang cukup, memberikan perhatian dan kasih sayang melainkan juga memberikan stimulus untuk membantuproses penyempurnaan jaringan saraf anak. Di awal pertumbuhan dan perkembangan orang tua memiliki peran dalam pemberian stimulus rangsangan taktil agar terbentuk koordinasi terhadap reflek dan gerakan bayi dengan baik (Chamida, 2009).

Stimulasi rangsangan yang mudah diberikan oleh orang tua secara aktif pada bayi dapat melalui stimulasi taktil dalam bentuk pijatan, menggerakkan kaki dan tangan bayi pada posisi ekstensi serta fleksi (Soedjatmiko, 2006).

Pijat bayi adalah terapi sentuh tertua dan terpopuler yang dikenal manusia. Pijat bayi telah lama dilakukan hampir di seluruh dunia termasuk di Indonesia dan diwariskan secara turun temurun. (Roesli, 2013).
Pijat bayi di Indonesia pelaksanaan di masyarakat desa masih dipegang oleh dukun bayi. Selama ini pemijatan tidak hanya dilakukan bila bayi sehat, tetapi juga pada bayi sakit atau rewel dan sudah menjadi rutinitas perawatan bayi setelah lahir (Prasetyono, 2009).

Pijat bayi adalah terapi sentuh tertua yang dikenal manusia dan yang paling populer. Dengan kata lain pijat bayi adalah seni perawatan kesehatan dan pengobatan yang dipraktekkan sejak berabad-abad silam. Manfaat pijat bayi, yaitu meningkatkan berat badan bayi, meningkatkan pertumbuhan bayi, meningkatkan daya tahan tubuh bayi, meningkatkan konsentrasi bayi dan membuat bayi tidur lebih lelap, meningkatkan ikatan kasih sayang orangtua dan anak (bonding), meningkatkan produksi ASI (Roesli, 2007).

Manfaat lain pijat bayi adalah meningkatkan perkembangan psikomotor dan perkembangan mentalnya. Hal ini ditunjukkan oleh penelitian yang dilakukan oleh Procianoy, Mendes dan Selveira (2009) tentang Massage therapy improves neurodevelopment outcome at two years corrected age for very low birth weight 
infants. Bayi yang baru lahir dengan berat lahir antara kurang lebih 750 gram dan kurang lebih 1500 gram dengan usia kehamilan kurang dari 32 minggu secara acak ditugaskan kepada ibu untuk melakukan terapi pijat. Pemberian terapi pijat dilakukan selama bayi tersebut dirawat di Rumah Sakit kemudian dievaluasi pada usia 2 tahun dan didapatkan hasil terjadinya peningkatan perkembangan psikomotor dan peningkatan perkembangan

Pijat bayi menjadi penyelesaian masalah dari setiap ibu yang mempunyai bayi. Dengan memijat bayi-bayi mereka, rasa percaya diri orang tua bertambah. Mereka belajar untuk memperhatikan dan memahami reaksi bayi pada saat disentuh, mengetahui perkembangan naluri alamianya, apa-apa yang disukai dan yang tidak disukainya, sehingga membuat para orang tua lebih mudah mengerti dan terkadang menjadi sabar disaat mereka tidak sanggup menenangkannya. Saat para orang tua memperhatikan dan mengenali reaksi anak-anaknya dan memberikan responnya, para bayi memberikan reaksinya kembali dan terbangunlah sebuah hubungan yang positif di antara mereka (Heath, 2007).
Beberapa penelitian terhadap pijat bayi memberikan hasil laporan terkait dengan manfaat pijat bayi seperti pijat bayi dapat meningkatkan berat badan, meningkatkan pertumbuhan, meningkatkan daya tahan tubuh, meningkatkan konsentrasi bayi dan membuat bayi tidur lebih lelap, membina bonding attachment antara orang tua dengan anak serta dapat meningkatkan produksi ASI ibu (Roesli, 2013).

Penelitian terkait dengan pijat bayi antara lain penelitian oleh Jin Jing et.al (2007) mendapatkan hasil bahwa pada bayi yang diberikan perlakuan pijat bayi dan latihan gerak, pertumbuhan dan perkembangan lebih cepat dibandingkan dengan bayi yang tidak diberikan pijat dan latihan gerak.

Penelitian lain dilakukan oleh Kachoosangy dan Aliabadi (2011) tentang pengaruh stimulasi taktilkinestetik terhadap perkembangan motorik pada bayi berat lahir rendah, dan didapatkan hasil bahwa bayi yang mendapatkan stimulasi taktil-kinestetik sebanyak 3 kali sehari selama 10 hari menunjukkan peningkatan perkembangan motorik, yang signifikan dibandingkan dengan kelompok kontrol.

Kalsum (2014) juga melakukan penelitian tentang peningkatan berat 
badan bayi melalui pemijatan. Hasil penelitian menunjukkan bahwa ada hubungan antara pemijatan dengan peningkatan berat badan bayi. Uji statistik menggunakan uji mann-whitney test didapatkan nilai $\mathrm{p}$-value 0,033 .

Hasil penelitian lain adalah penelitian yang dilakukan oleh Inal dan Yildiz (2012) dalam penelitiannya didapatkan kesimpulan bahwa bayi sehat lahir cukup bulan yang mendapatkan tindakan pijat perkembangan mentalmotor lebih signifikan dibandingkan dengan kelompok yang tidak mendapatkan tindakan.

Andini (2014) juga melakukan penelitian tentang pengaruh pijat bayi terhadap perkembangan neonatus. Hasil uji statistik Mann-Whitney didapatkan $p$ value sebesar 0,000 lebih kecil dari nilai $\alpha$ $(0,05)$ yang berarti ada pengaruh yang signifikan antara pijat bayi terhadap perkembangan neonatus.

Menurut penelitian Field, et.al (2011) menunjukkan bahwa 20 bayi prematur (berat badan 1.280 dan 1.176 gr), yang dipijat selama 3 kali 15 menit selama 10 hari, terjadi kenaikan berat badan 20\% - 47\% per hari, lebih dari yang tidak dipijat. Tujuan penelitian ini adalah untuk mengidentifikasi efektifitas pijat bayi terhadap peningkatan berat badan bayi prematur.
Penelitian Field, et.al (2011) menunjukkan bahwa pada bayi yang dipijat akan terjadi peningkatan tonus nervus vagus (saraf otak). Peningkatan aktivitas nervus vagus akan meyebabkan peningkatan produksi enzim penyerapan seperti gastrin dan insulin sehingga penyerapan makanan menjadi lebih baik. Kondisi inilah yang dapat menjelaskan berat badan bayi yang dipijat lebih meningkat (Roesli, 2007).

Meskipun pengetahuan ini masih baru, namun pijat bayi telah dipopulerkan di Sumatera Barat. Sekitar $36 \%$ petugas kesehatan telah memberikan penyuluhan tentang manfaat dan cara pijat bayi kepada ibu yang mempunyai bayi. Pijat bayi ini sudah dilaksanakan juga oleh BPS Bunda. Berdasarkan hasil survey yang dilakukan di BPS Bunda didapatkan ibu yang berkunjung ke BPS Bunda ada 80 orang, yang melakukan pijat bayi sebanyak $40 \%$ dan yang tidak melakukan pijat bayi sebanyak 25\%. Berdasarkan hasil wawancara yang dilakukan dengan 4 orang tua bayi ada 3 orang tua yang rutin melakukan pijat bayi pada anaknya karena orang tua bayi ingin tubuh anaknya lebih kuat dan nafsu makannya lebih bagus dan ada 1 orang tua yang tidak rutin melakukan pijat bayi 
karena sebagian orang tua takut anaknya melakukan pijat bayi, sehingga dari data yang didapatkan ada juga bayi yang tidak mengalami kenaikan berat badan.

Dari data tersebut maka peneliti ingin meneliti tentang, "Pengaruh Pemberian Pijat Bayi Terhadap Kenaikan Berat Badan Bayi Umur 0-6 Bulan di BPS Bunda.

\section{METODE PENELITIAN}

Penelitian ini merupakan penelitian Experimental Desaign. Dengan menggunakan Quasy Experiment yaitu sampel A diberikan perlakuan X dan sampel B tidak diberikan perlakuan, keduanya kemudian diobservasi dan dilakukan secara berulang-ulang (Notoadmotjo, 2012). Penelitian ini dilakukan di BPS Bunda Bukittinggi pada bulan Mei sampai Juni tahun 2015.

Sampel dalam penelitian ini adalah bayi berumur 0-6 bulan yang berkunjung ke BPS Bunda yang berjumlah 24 orang yang terdiri dari 12 orang yang diberikan pijat bayi dan 12 orang lagi yang tidak diberikan pijat bayi.

Data yang dikumpulkan pada saat survei yaitu melalui hasil wawancara dengan orang tua bayi dan dengan melakukan survei yang dilakukan dengan melihat data-data bayi yang melakukan pijat bayi. Data yang dikumpulkan termasuk pengambilan sampel Nonprobability Sampling dengan metode sampling sistemis dengan cara peneliti memberikan nomor 1-24 kepada responden (Hastono, 2006). Yang terpilih nomor urut ganjil dijadikan sebagai responden, didapatkan responden sebanyak 24 orang responden sehingga didapatkan 12 orang respondendiberikan pijat bayi dan 12 orang responden lagi tidak diberikan pijat bayi.

Setelah mendapatkan izin dari BPS, peneliti memberikan informasi kepada ibu-ibu bayi yang akan dijadikan sampel dalam penelitian ini dan setiap ibu berhak untuk menolak atau bersedia bayinya dijadikan sebagai sampel penelitian. Bagi mereka yang bersedia menjadi sampel diminta untuk menandatangani Informed Consent sebagai bukti kesediaan menjadi sampel.

Analisa data yang digunakan yaitu analisa dengan uji T. Di dalam memilih langkah pendekatan penelitian, telah dikemukakan beberapa desain eksperimen diantaranya telah disertai rumus atau cara analisis datanya. Untuk testing signifikan, maka digunakan Dependen T-test. 


\section{HASIL DAN PEMBAHASAN}

\section{Hasil}

Hasil penelitian dijabarkan dalam dua bentuk yaitu analisa univariat dan analisa bivariat.

Hasil analisa univariat menunjukkan bahwa dari 24 responden ada 12 orang (100\%) responden yang diberikan pijat bayi dan 12 orang (100\%) responden yang tidak diberikan pijat bayi. Kenaikan berat badan pada bayi kelompok intervensi mengalami kenaikan $\geq 600 \mathrm{gr} /$ bulan yaitu sekitar (100\%) dan pada bayi kelompok kontrol mengalami kenaikan < 600 gr/ bulan yaitu sekitar (100\%).

Tabel 1. Rerata Kenaikan Berat Badan Bayi yang diberikan Pijat Bayi Dan yang Tidak Diberikan Pijat Bayi

\begin{tabular}{lllll}
\hline No & $\begin{array}{c}\text { Pemberian } \\
\text { Pijat Bayi }\end{array}$ & N & Mean & $\begin{array}{c}\text { P- } \\
\text { Value }\end{array}$ \\
\hline 1 & Naik & 12 & 800 & 0,000 \\
2 & Tidak Naik & 12 & 233.33 & \\
\hline \multicolumn{5}{l}{ Sumber : Hasil Pengolahan }
\end{tabular}

Pada tabel di atas didapatkan rerata kenaikan berat badan bayi yang diberikan pijat bayi adalah 800 gram/bulan dan rerata kenaikan berat badan bayi yang tidak diberikan pijat bayi adalah 233.33gram/bulan. Hasil uji statistik didapatkan nilai $\mathrm{p}$ value $=0,000$ berarti terlihat ada perbedaan yang signifikan antara rerata kenaikan berat badan yang di berikan pijat bayi dan yang tidak di berikan pijat bayi di BPS Bunda.

\section{Pembahasan}

Pada penelitian ini didapatkan hasil uji statistik nilai $\mathrm{p}$ value $=0,000$ yang ada perbedaan yang signifikan antara rerata kenaikan berat badan yang di berikan pijat bayi dan yang tidak di berikan pijat bayi.

Hal ini sejalan dengan pendapat Roesli (2013) yang menyatakan bahwa manfaat pijat bayi dapat meningkatkan berat badan dan pertumbuhan, meningkatkan daya tahan tubuh, meningkatkan ikatan kasih sayang orang tua dan anak (bonding) dan meningkatkan produksi ASI.

Pijat bayi bermanfaat merangsang syaraf motorik, memperbaiki pola tidur, membantu pencernaan dan meningkatkan ketenangan emosional anak, selain menyehatkan tubuh dan otot-otot. Bayi yang dipijat dengan baik dan teratur dapat tumbuh lebih sehat dan berkembang lebih baik (Soetjiningsih, 2011).

Penelitian ini hampir senada dengan penelitian yang dilakukan oleh Jin Jing, et.al (2007) yang menyatakan pemberian pijatan dan latihan gerak 
dapat meningkatkan perkembangan fisik dan kecerdasan bayi mulai dari bayi lahir hingga bayi usia 6 bulan dengan $p=$ 0,010 .

Penelitian ini juga didukung oleh penelitian yang dilakukan Kalsum (2014) tentang peningkatan berat badan bayi melalui pemijatan. Hasil penelitian menunjukkan bahwa ada hubungan antara pemijatan dengan peningkatan berat badan bayi. Uji statistik menggunakan uji mann-whitney test didapatkan nilai p-value 0,033 .

Pemijatan juga dapat meningkatkan aktivitas neurotransmitter serotonin, yaitu meningkatkan kapasitas sel reseptor yang berfungsi meningkat glucocorticoid (adrenalin/suatu hormone stres). Proses ini akan menyebabkan terjadinya penururunan kadar hormon adrenalin (hormon stres). Penurunan kadar hormon stres ini akan meningkatkan daya tahan tubuh, terutama IgM dan IgG (Subakti dan Anggraini, 2008).

Sedangkan dari beberapa penelitian berikut menunjukkan beberapa manfaat dari terapi pijat selain meningkatkan berat badan bayi yaitu seperti penelitian yang dilakukan Hayati (2012) menyebutkan pijat bayi berpengaruh dalam meningkatkan kuantitas tidur bayi umur 3-6 bulan yang dipijat 2 kali sehari selama 15 hari pada pagi hari sebelum mandi dan malam hari sebelum tidur.

Sedangkan penelitian yang dilakukan oleh Fitriani dan Nurhidayati (2007) kepada 20 bayi berusia diatas 6 bulan, didapatkan hasil bahwa 14 bayi dengan peningkatan nafsu makan lebih dari biasa, 3 bayi dengan peningkatan nafsu makan lebih sedikit dan 3 bayi dengan nafsu makan tetap, dengan demikian pengaruh semakin sering bayi dipijat dengan frekuensi yang teratur, peningkatan nafsu makan bayi akan terus baik.

Hasil penelitian ini sejalan dengan penelitian yang telah dilakukan oleh Field, et.al (2011) menunjukkan bahwa pada bayi cukup bulan yang berusia 1-3 bulan, yang dipijat 15 menit, 2 kali seminggu selarna 6 minggu, akan mengalami kenaikan berat badan yang lebih dari biasanya.

Hal ini juga sejalan dengan penelitian yang dilakukan oleh Kachoosangy dan Aliabadi (2011) tentang pengaruh stimulasi taktilkinestetik terhadap perkembangan motorik pada bayi berat lahir rendah, dan 
didapatkan hasil bahwa bayi yang mendapatkan stimulasi taktil-kinestetik sebanyak 3 kali sehari selama 10 hari menunjukkan peningkatan perkembangan motorik, yang signifikan dibandingkan dengan kelompok kontrol.

Manfaat lain setelah dilakukan pemijatan membuat bayi nyaman (relaksasi) dan mengantuk (cepat tertidur). Kebanyakan bayi tidur dalam waktu lama setelah pemijatan. Selain lama, bayi tidur lebih lelap (tenang), tidak rewel, pola tidur lebih baik dan meningkatkan kesiagaan saat bangun. Manfaat lainnya yang dirasakan oleh ibu yaitu bayi lebih kuat menyusu kepada ibunya, peningkatan nafsu makan terjalin bonding attachment lebih dekat antara ibu dan bayi.

Hal ini didukung oleh pendapat Roesli (2008) yang mengemukakan bahwa pemijatan juga dapat membuat bayi tidur lebih lelap dan meningkatkan kesiagaan atau konsentrasi. Hal ini disebabkan pijatan dapat mengubah gelombang otak. Pengubahan ini terjadi dengan cara menurunkan gelombang alpha dan meningkatkan gelombang beta serta tetha, yang dapat dibuktikan dengan penggunaan EEG/ Electro encephalogram.
Analisa peneliti, pada kelompok perlakuan terlihat bahwasanya bayi yang mengalami kenaikan berat badan $\geq 600$ gr/bulan yaitu 12 orang (100\%). Hal ini menunjukan bahwa semua bayi yang diberikan pijat tidak ada yang tidak mengalami kenaikan berat badan. Sedangkan pada kelompok kontrol terlihat bahwasanya tidak ada yang bayi yang mengalami kenaikan berat badan yang $<600 \mathrm{gr} /$ bulan dan pada kelompok kontrol ini semua responden mengalami berat badan $<600 \mathrm{gr} /$ bulan. Disini terlihat bahwa ada perbedaan yang signifikan antara rerata kenaikan berat badan yang di berikan pijat bayi dan yang tidak diberikan pijat bayi umur 0-6 bulan, kenaikan berat badan pada bayi dengan umur yang sama, merupakan suatu hal yang wajar, karena perbedaan berat badan tersebut tergantung dari berbagai faktor antara lain faktor genetik, lingkungan, sehingga tidak menutup kemungkinan pada setiap responden penelitian mengalami salah satu atau lebih dari faktor tersebut sehingga persepsi terhadap berat badan bayi tersebut bisa jadi meningkat, tergantung dari seberapa sering stimulus dalam bentuk tindakan pijat bayi yang diberikan pada bayi. 
Sentuhan dan pijat pada bayi setelah kelahiran dapat memberikan jaminan adanya kontak tubuh berkelanjutan yang dapat mempertahankan perasaan aman pada bayi. Ilmu kesehatan modern telah membuktikan secara ilmiah bahwa terapi sentuhan dan pijat pada bayi mempunyai banyak manfaat terutama bila dilakukan sendiri oleh orang tua bayi.

Bayi yang diberikan pijat akan lebih relaks dan beristirahat dengan efektif, sehingga pada saat bangun membawa energi cukup untuk beraktifitas. Secara optimal bayi akan cepat lapar sehingga nafsu makan meningkat dan kenaikan berat badan terjadi secara optimal.

\section{KESIMPULAN}

Berdasarkan hasil penelitian dapat disimpulkan bahwa didapatkan 12 orang bayi yang diberikan pijat dan 12 orang lagi tidak diberikan pijat. Rerata kenaikan berat badan bayi yang diberikan pijat adalah 800.00 gram/bulan dan rerata berat badan bayi yang tidak diberikan pijat bayi adalah 233.33 gram/bulan. Hasil uji statistik didapatkan nilai $p$-value $=0,000$ berarti terlihat ada perbedaan yang signifikan antara rerata kenaikan berat badan bayi yang diberikan pijat bayi dan yang tidak diberikan pijat umur 0-6 bulan di BPS Bunda.

\section{SARAN}

Hasil penelitian ini diharapkan menjadi motivasi untuk mengikuti pelatihan pijat bayi serta perlu adanya sosialisasi lebih lanjut tentang pijat bayi pada masyarakat. Disarankan kepada pimpinan BPS agar lebih meningkatkan program pijat bayi agar lebih banyak lagi masyarakat yang tahu tentang adanya program pijat bayi yang telah ada di BPS bunda pada sekarang ini.

\section{UCAPAN TERIMAKASIH}

Ucapan terima kasih kepada Ketua Yayasan dan Direktris Akper Nabila Padang Panjang yang telah memberikan motivasi dan memfasilitasi peneliti untuk melakukan penelitian dan terimakasih juga peneliti ucapkan kepada pimpinan dan seluruh staff di BPS Bunda yang telah memberikan izin kepada peneliti untuk melakukan penelitian serta rekan-rekan staf dan Dosen Akper Nabila Padang Panjang yang telah menyemangati peneliti dalam menyelesaikan laporan penelitian ini.

\section{DAFTAR PUSTAKA}

Andini, (2014). Pengaruh Pijat Bayi terhadap Perkembangan Neonatus. 
JOM PSIK. Vol. 1. No.2 Oktober 2014.

Chamida, A, N. (2009). Pentingnya Stimulasi Dini Bagi Tumbuh Kembang Otak Anak. Yogyakarta : Jurusan pendidikan Luar Biasa UNY.

Field, T., Diego, M., Medina, L., Delgado, J. \& Hernandez, A. (2011). Yoga and Massage Therapy Reduce Prenatal Depression and Prematurity. University of Miami School of Medicine : NIH Public Access.

Fitriani, L \& Nurhidayati, N. (2007). Pengaruh Pijat Bayi terhadap Peningkatan Nafsu Makan Bayi Usia Di atas 6 Bulan di Poli Klinik Fisioterapi Handicamp International Wedi Klaten. Semarang : UNS.

Hastono, S, P. 2006. Basic Data Analysis. Jakarta : EGC

Hayati, 2012. Efektifitas Pijat Bayi terhadap Kuantitas Tidur pada Bayi Umur 3-6 Bulan. PSIK UR. Tidak dipublikasikan.

Heath, A \& B, N. (2007). Baby Massage : The Calming Power of Touch. Jakarta : Dian Rakyat.

Inal, Sevil \& Yildiz, Suzan. (2012). The Effect of Baby Massage on MentalMotor Development of Healthy Full Term Baby. Turkey : HealthMED.

Jing, Jin et.al. (2007). Massage and Motion Training For Growth and Development of Infants. Guangzhou : World J Pediatric

Kachoosangy, R. A., \& Aliabadi, F. (2011). Effect of tactilekinesthetic stimulation on motor development of low birth weight neonates. Iranian Rehabilitation Journal, Vol. 9.
Kalsum, U. (2014). Peningkatan Berat Badan Bayi Melalui Pemijatan. Jurnal Keperawatan Indonesia. Vol. 17. No. 1 Maret 2014, Hal. 25-29. PISSN 1410-4490, EISSN 2354-9203.

Notoatmodjo, S, 2012. Metodologi Penelitian Kesehatan. Edisi Revisi Cetakan Kedua. Jakarta : Rineka Cipta.

Prasetyono, 2009. Kenaikan Berat Badan Bayi. Jakarta : EGC

Procianoy, Mendes, \& Selveira. (2009). Massage therapy improves neurodevelopment outcome at two years corrected age for very low birth weight infants 86 (1), 7-11.

Roesli, U. 2007. Pedoman Pijat Bayi. Jakarta : Trubus Agriwidya . 2008. Pedoman Pijat Bayi. Jakarta : Trubus Agriwidya 2013. Pedoman Pijat Bayi. Jakarta : Pustaka Pembangunan Swadaya

Soetijiningsih. 2011. Panduan Pijat Bayi. Yogyakarta : Buku Kita

Subakti, A. 2008. Keajaiban Pijat Bayi. Jakarta : Qultum Media

Soedjatmiko, (2006). Pentingnya Stimulasi Dini untuk Merangsang Perkembangan Bayi dan Balita Terutama pada Bayi Risiko Tinggi. Jakarta : Sari Pediatri Vol. 8 No.3.

World Health Organization, (2013). Health Topic : Infant, Newborn. Geneva : WHO 